\title{
Physiology and molecular biology of aquatic cyanobacteria
}

\author{
George S. Bullerjahn ${ }^{1 *}$ and Anton F. Post ${ }^{2}$ \\ ${ }^{1}$ Department of Biological Sciences, Bowling Green State University, Bowling Green, OH, USA \\ ${ }^{2}$ Marine Biological Laboratory Woods Hole, Woods Hole, MA, USA \\ *Correspondence: bullerj@bgsu.edu
}

Edited and reviewed by:

Jonathan P. Zehr, University of California, Santa Cruz, USA

Keywords: cyanobacteria, HABs, Prochlorococcus, Synechococcus, nitrogen fixation

Cyanobacteria thrive in every illuminated aquatic environment known, contributing at least $25 \%$ of primary productivity worldwide. Given their importance in carbon and nutrient cycles, cyanobacteria are essential geochemical agents that have shaped the composition of the Earth's crust, oceans and atmosphere for billions of years. The high diversity of cyanobacteria is reflected in the panoply of unique physiological adaptations across the phylum, including different strategies to optimize light harvesting or sustain nitrogen fixation, but also different lifestyles like psychrotrophy, and oligotrophy. Some cyanobacteria produce secondary metabolites of cryptic function, many of which are toxic to eukaryotes. Consequently, bloom-forming toxic cyanobacteria are global hazards that are of increasing concern in surface waters affected by anthropogenic nutrient loads and climate change. While focusing on cyanobacteria in aquatic environments, the collection of papers herein touches on this broad range of topics.

Regarding the role of cyanobacteria in the ocean, the importance of the unicellular picocyanobacteria is paramount. Indeed, Synechococcus and Prochlorococcus are the abundant genera in the oligotrophic open sea. Given that cyanobacteria are under regular assault imposed by photooxidative stresses, and that such stresses constrain photosynthetic performance, the paper by Mella-Flores et al. (2012) describes different strategies employed by model strains of Synechococcus and Prochlorococcus to high light and UV. Nonetheless, in the ocean, Synechococcus is composed of several clades that likely define particular ecotypes. Detection and enumeration of distinct Synechococcus clades is essential in understanding how these organisms co-exist with one another. To this end, Ahlgren and Rocap (2012) developed a suite of qPCR tools enabling a thorough analysis of Synechococcus community structure and dynamics.

Nitrogen fixation by the unicellular Crocosphaera watsonii is now recognized to be a significant source of new $\mathrm{N}$ to marine environments. Two papers describe physiological properties of Crocosphaera relevant to their ecological importance. Sohm et al. (2011) demonstrate that a strain of C. watsonii produces high amounts of extracellular polysaccharides. The high level of organic carbon production suggests that this strain may directly support significant heterotrophy in the marine C cycle. Given that arsenate is a toxic anion that can interfere with the transport and metabolism of phosphate, Dyhrman and Haley (2011) report mechanisms of arsenate resistance in Crocosphaera, whose habitat includes P-limited ocean gyres. Such regions often have high arsenate:phosphate ratios, thus detoxification mechanisms are an important strategy for $\mathrm{N}$ fixation in these oligotrophic regions.

The structure and physiological performance of arctic cyanobacterial mats is of particular interest, given their dominant contribution to biomass at high latitudes, and the stresses imposed by global warming on such fragile environments. Lionard et al. (2012) examine the composition of an artic microbial mat, and demonstrate the robust adaptation of the cyanobacteria to osmotic stress, a likely outcome of climate change.

The characterization of chlorophyll- $b$ containing Prochlorothrix spp. by Pinevich et al. (2012) indicate that despite the scarcity of this genus in aquatic environments, molecular methods suggest it is more widely distributed. The authors compare the physiological characteristics of the two known species and discuss the evolution of their light harvesting apparatus.

Four papers explore the physiology of bloom-forming and toxic cyanobacteria. Kaplan et al. (2012) address the enigmatic function of the microcystins and cylindrospermopsins, describing experimental evidence for their role in cell-cell communication among bloom-formers. Sukenik et al. (2012) explore the spread of Aphanizomenon and Cylindrospermopsis to temperate freshwater environments. The appearance of such blooms is a likely consequence of global warming along with anthropogenic nutrient load, leading to a sustained invasion of into the middle latitudes. Given that management of phosphorus inputs is a strategy for limiting algal blooms in freshwaters, Saxton et al. (2012) describe the phosphorus quotas (intracellular and total) of the toxic colonial cyanobacterium, Microcystis aeruginosa. In response to increased phosphorus, Microcystis exhibited a higher cell $\mathrm{P}$ quota, yet a stable growth rate compared to lower phosphorus treatments. Such work has implications in modeling Microcystis blooms from P loadings into freshwaters. Gagnon and Pick (2012) contribute a study showing that the potent neurotoxin anatoxin-a is associated with nitrogen availability in Aphanizomenon. Understanding environmental cues for toxin production is essential in ultimately mitigating bloom toxigenicity.

Together, these important contributions cover many of the issues tackled in the field today: the role of cyanobacteria in the global carbon and nutrient cycles, cyanobacterial evolution, the adaptation of cyanobacteria to climate change and the consequences of toxigenicity. The studies described in this collection provide an excellent introduction to these topics, while providing 
important clues regarding the future directions that studies of cyanobacteria will take.

\section{REFERENCES}

Ahlgren, N. A., and Rocap, G. (2012). Diversity and distribution of marine Synechococcus: multiple gene phylogenies for consensus classification and development of qPCR assays for sensitive measurement of clades in the ocean. Front. Microbiol. 3:213. doi: 10.3389/fmicb.2012.00213

Dyhrman, S. T., and Haley, S. T. (2011). Arsenate resistance in the unicellular marine Diazotroph Crocosphaera watsonii. Front. Microbiol. 2:214. doi: 10.3389/fmicb.2011.00214

Gagnon, A., and Pick, F. R. (2012). Effect of nitrogen on cellular production and release of the neurotoxin anatoxin-a in a nitrogen-fixing cyanobacterium. Front. Microbiol. 3:211. doi: 10.3389/fmicb.2012.00211

Kaplan, A., Harel, M., Kaplan-Levy, R. N., Hadas, O., Sukenik, A., and Dittmann, E. (2012). The languages spoken in the water body (or the biological role of cyanobacterial toxins). Front. Microbiol. 3:138. doi: 10.3389/fmicb.2012.00138

Lionard, M., Péquin, B., Lovejoy, C., and Vincent, W. F. (2012). Benthic cyanobacterial mats in the high Arctic: multi-layer structure and fluorescence responses to osmotic stress. Front. Microbiol. 3:140. doi: 10.3389/fmicb.2012.00140

Mella-Flores, D., Six, C., Ratin, M., Partensky, F., Boutte, C., Le Corguillé, G., et al. (2012). Prochlorococcus and Synechococcus have evolved different adaptive mechanisms to cope with light and UV stress. Front. Microbiol. 3:285. doi: 10.3389/fmicb.2012.00285

Pinevich, A., Velichko, N., and Ivanikova, N. (2012). Cyanobacteria of the genus Prochlorothrix. Front. Microbiol. 3:173. doi: 10.3389/fmicb.2012.00173
Saxton, M. A., Arnold, R. J., Bourbonniere, R. A., McKay, R. M. L., and Wilhelm, S. W. (2012). Plasticity of total and intracellular phosphorus quotas in Microcystis aeruginosa cultures and Lake Erie algal assemblages. Front. Microbiol. 3:3. doi: 10.3389/fmicb.2012.00003

Sohm, J. A., Edwards, B. R., Wilson, B. G., and Webb, E. A. (2011). Constitutive extracellular polysaccharide (EPS) production by specific isolates of Crocosphaera watsonii. Front. Microbiol. 2:229. doi: 10.3389/fmicb.2011.00229

Sukenik, A., Hadas, O., Kaplan, A., and Quesada, A. (2012). Invasion of Nostocales (cyanobacteria) to subtropical and temperate freshwater lakes physiological, regional, and global driving forces. Front. Microbiol. 3:86. doi: $10.3389 /$ fmicb.2012.00086

Conflict of Interest Statement: The authors declare that the research was conducted in the absence of any commercial or financial relationships that could be construed as a potential conflict of interest.

Received: 17 June 2014; accepted: 26 June 2014; published online: 16 July 2014. Citation: Bullerjahn GS and Post AF (2014) Physiology and molecular biology of aquatic cyanobacteria. Front. Microbiol. 5:359. doi: 10.3389/fmicb.2014.00359 This article was submitted to Aquatic Microbiology, a section of the journal Frontiers in Microbiology.

Copyright (c) 2014 Bullerjahn and Post. This is an open-access article distributed under the terms of the Creative Commons Attribution License (CC BY). The use, distribution or reproduction in other forums is permitted, provided the original author(s) or licensor are credited and that the original publication in this journal is cited, in accordance with accepted academic practice. No use, distribution or reproduction is permitted which does not comply with these terms. 